\title{
Negative Feedback on Tripadvisor: A Hotel’s Nightmare
}

\author{
Barrie Goldsmith \\ Australian Travel \& Tourism Lawyers, Sydney, Australia
}

\begin{abstract}
In today's electronic world, an increasing and troubling issue for an accommodation provider is the appearance of a negative review on TripAdvisor or a similar site. Businesses face a growing difficulty in having these negative reviews removed. Whilst voluntary removal is undoubtedly the preferred course, which is frequently not what happens. Instead, businesses must deal with the prospect of intricate and costly litigation.
\end{abstract}

Keywords: review, negative, removal, defamatory, damage, reputation

\section{Introduction}

The objective of this paper is to try and create increased awareness of the difficulties often faced by business proprietors in having negative reviews removed and to encourage business proprietors to try and resolve grievances of consumers before matters reach the point that a disgruntled consumer will post a negative review online.

\section{An Example of the Devastating Damage That Can be Caused by a Negative Review}

An extreme example of a negative review on TripAdvisor was the ranking of a hotel in USA as “The Dirtiest Hotel in America 2011".

The litigation that resulted from that ranking is discussed below.

The reasons for negative reviews. Negative reviews usually appear for one of the two reasons as follows:

(1) A disgruntled guest wishing to record his or her complaints;

(2) A competitor seeking to damage the business or reputation of the accommodation provider against which the negative review is recorded.

\section{TripAdvisor - Statistics}

There are some fascinating statistics in relation to TripAdvisor and other travel sites:

(1) As of the beginning of 2016, TripAdvisor achieved the milestone of featuring more than 320 million travel reviews and opinions (TripAdvisor, 2016a);

(2) TripAdvisor has about 96 million marketable members worldwide (TripAdvisor, 2016b);

(3) About 200 contributions are posted to the TripAdvisor website every minute (TripAdvisor, 2016b);

(4) The TripAdvisor website carries 53 million candid user-submitted images (TripAdvisor, 2016b);

(5) The content on TripAdvisor sites influenced \$478 billion of travel spending in 2014 (Oxford Economics, 2016);

Barrie Goldsmith, Principal, Australian Travel \& Tourism Lawyers. Email: barrie@gold-law.com.au.

${ }^{1}$ Kenneth M. Seaton, d/b/a Grand Resort Hotel \& Convention Ctr. v. TripAdvisor, LLC (3:11-cv-00549, E.D. Tenn. 22 August, 2012). 
(6) Over 1.8 million accommodations, 4 million restaurants, and 655,000 attractions are represented on the website (TripAdvisor, 2016b);

(7) TripAdvisor operates in 48 markets including the U.S., U.K., China, and Malaysia, in 28 different languages and with instant booking available in over 11 countries (TripAdvisor, 2016c);

(8) Through all of its sites, TripAdvisor hosts approximately 340 million unique users each month. It is the largest travel site in the world (TripAdvisor, 2016a).

There is no doubt that its achievements and growth are spectacular, particularly for a company that was only founded 16 years ago. TripAdvisor and associated sites will become increasingly more influential in travel arrangements. According to a recent U.S. survey, more than $75 \%$ of respondents who were interviewed said that they share travel experiences via social networks and some $64 \%$ said that they often referred to a travel research site such as TripAdvisor for travel inspiration (TripAdvisor, 2012).

\section{Guidelines for Posting and Negative Reviews}

TripAdvisor publishes its guidelines for posting on its forums. Generally, it will remove any posts that do not meet its guidelines although it will only do so reluctantly because it believes that all posts keep the forums welcoming and conducive to helpful discussion.

TripAdvisor also has its own guidelines where a negative review has been posted. It has a specific content integrity team responsible for investigating concerns about reviews posted on its site. It particularly treats very seriously allegations of blackmail or threatened behaviour by a guest.

One of the practices of TripAdvisor is for the accommodation provider to post a response immediately underneath the negative review. TripAdvisor encourages this practice as an effective marketing tool to emphasise to travelers that the experience in the review is not the norm, or steps are being taken to correct the condition. However, that frequently does not satisfy the accommodation provider, particularly where the accommodation provider is adamant that there was no basis at all for the negative review. In that situation, it is often necessary to invoke TripAdvisor's "Notice and Takedown Procedure”.

\section{Notice and Takedown Procedure}

This procedure can be invoked where it is alleged that defamatory comments have been published or intellectual property rights have been infringed.

TripAdvisor provides a specific form of notice that it requires to be completed and sent to a specified address in Massachusetts. As a matter of practice, TripAdvisor will inevitably not remove any posts where it is satisfied that the statements made are true, or possibly may be true, or where they reflect an honest opinion.

Upon receipt of such a notice, TripAdvisor will investigate the complaint and determine whether or not to remove the review complained of. If it does not agree to do so, then the accommodation provider needs to consider the prospect of legal action.

\section{Legal Action}

Inevitably, the accommodation provider wishes to contemplate legal action against the person who posted the review. This is notwithstanding that, at least according to Australian law, it is the publisher of defamatory material who is liable. It is possible for website hosts to be liable for the publication of defamatory material, even when they did not post it, provided that they have been given notice of the existence of the defamatory material, they have been required to remove it and they have failed to do so. 
Nonetheless, as a matter of practicality, accommodation providers generally look to claiming against the author of the review, the person who posted it on the relevant website. The principal reason for that is that, even if the accommodation provider is able to convince one website host to remove the negative review, the author of the review may then simply post the same or a substantially similar review on another site. Accordingly, the prevailing "philosophy" is to go to the source of the problem.

One of the difficulties most commonly encountered by an accommodation provider wishing to take legal action is to identify the person who actually posted the review. User names abound and it is extremely rare for the identity of the person who posted the review to be shown. This is particularly the case where a negative review is posted by a competitor of the accommodation provider with the deliberate aim of damaging the business and reputation of that provider.

Inevitably, requests to website hosts such as TripAdvisor will not produce, voluntarily, information about the identity of the reviewer. Websites such as TripAdvisor, Facebook and the like will only provide that information pursuant to a court order, whether by way of subpoena or otherwise.

\section{Preliminary Discovery}

In Australia, it is possible to apply for an order commonly known as "an order for preliminary discovery". Application can be made for such an order against, for example, website hosts to enable a proposed plaintiff to obtain information about the identity or whereabouts of a proposed defendant. Accordingly, that procedure involves an initial and distinct action against the host, such as TripAdvisor.

In considering such an application, it is also necessary to consider jurisdictional issues. TripAdvisor's terms and conditions of business provide that use of its website is governed by the laws of the State of Massachusetts although such a term and condition does not necessarily usurp the laws of other countries (see the recent judgment of a Scottish Court).

If evidence of the identity of the person who posted the review can be obtained, then the accommodation provider can commence proceedings for defamation.

\section{Case Studies - TripAdvisor}

\section{Case Studies - In Favour of TripAdvisor}

In a recent judgment of the Court of Tennessee in USA, the Court granted TripAdvisor's motion to dismiss the plaintiff's claim in which the plaintiff was ranked as the dirtiest hotel in America 2011. ${ }^{2}$ The Court granted the motion primarily finding that what was said reflected nothing more than the opinions of TripAdvisor's users. The legal principles invoked in that case are not necessarily the same as the legal principles that would be invoked in Australia.

\section{Case Studies - Against TripAdvisor}

In February 2012, the Advertising Standards Authority (2012) of the UK upheld a complaint by KwikChex, an online reputation management firm, that it was misleading for TripAdvisor to have said that what was posted on its website were "reviews you can trust" and "read reviews from real travelers".

Further, in October 2012, the owner of a small guesthouse in Scotland, despite initial opposition from TripAdvisor, obtained a concession from it that a Scottish Court did have jurisdiction to hear and determine a claim by him in relation to false criticisms posted on its website. That finding is broadly consistent with a finding that would be made in similar circumstances in Australia (Daily Mail, 2012).

\footnotetext{
${ }^{2}$ Kenneth M. Seaton, d/b/a Grand Resort Hotel \& Convention Ctr. v. TripAdvisor, LLC (3:11-cv-00549, E.D. Tenn. 22 August, 2012).
} 


\section{Conclusion}

Whilst websites such as TripAdvisor have sensible and balanced guidelines to deal with negative reviews, they are inevitably placed in a difficult situation when a reviewer is adamant that the negative review is true and justified and the accommodation provider is equally as adamant that it is untrue and defamatory. It is frequently alleged that negative reviews have been posted maliciously by the reviewer because the accommodation provider was unwilling to meet unreasonable demands made by the reviewer during a stay at the accommodation.

Unless TripAdvisor can be persuaded to remove the post, the accommodation provider may be left with no alternative other than to commence legal proceedings and which in fact may comprise two sets of proceedings, one to obtain evidence of the identity of the person who posted the review and the other by way of defamation. Needless to say, the entire exercise can be demanding as well as costly.

\section{References}

Advertising Standards Authority. (2012). ASA Ruling on TripAdvisor LLC. Retrieved from https://www.asa.org.uk/Rulings/Adjudications/2012/2/TripAdvisor-LLC/SHP_ADJ_166867.aspx\#.V6P3lFt96Wg

Daily Mail. (2012). Tiny B\&B deals blow for TripAdvisor as it wins landmark victory after visitors posted bad reviews. Retrieved from http://www.dailymail.co.uk/news/article-2216502/Tiny-B-amp-B-deals-blow-Tripadvisor-wins-landmark-victory-visitors-posted-b ad-reviews.html

Kenneth M. Seaton, d/b/a Grand Resort Hotel \& Convention Ctr. v. TripAdvisor, LLC (3:11-cv-00549, E.D. Tenn. 22 August, 2012).

Oxford Economics. (2016). The global economic contribution of TripAdvisor.

TripAdvisor. (2012). Survey reveals three quarters of U.S. travelers sharing trip experiences on social network.

TripAdvisor. (2016a). Quarter 1, 2016 results, 4.

TripAdvisor. (2016b). Fact sheet. Retrieved from https://www.tripadvisor.com.au/PressCenter-c4-Fact_Sheet.html

TripAdvisor. (2016c). Tripadvisor expands its instant booking marketplace to nine more English-speaking countries. 